\title{
ACESSIBILIDADE NA EDUCAÇÃO SUPERIOR TAMBÉM ENVOLVE O TRABALHO PEDAGÓGICO
}

\section{ACCESSIBILITY IN HIGHER EDUCATION INVOLVES PEDAGOGICAL WORK AS WELL}

\author{
Eliane Aparecida Piza CANDIDO ${ }^{i}$ \\ Claudia Regina Siena do NASCIMENTO ${ }^{\text {ii }}$ \\ Morgana de Fátima Agostini MARTINS ${ }^{\text {iii }}$
}

RESUMO: Esta pesquisa apresenta um estudo sobre a inclusão na Educação Superior e as práticas pedagógicas que podem contribuir para a realização dessa inclusão, salientando a dívida histórica que o Brasil possui baseada na exclusão e segregação de pessoas com deficiência que estão em constante luta por seus direitos, que sendo pouco a pouco garantidos têm um maior foco na Educação Básica e, atualmente, objetiva envolver de forma mais efetiva a Educação Superior. A pesquisa de abordagem qualitativa utilizou como procedimento metodológico um levantamento bibliográfico sobre o tema, bem como a verificação dos documentos legais nacionais, que explicitam os compromissos políticos brasileiros na incessante luta pela conquista da inclusão educacional e também a inclusão social. Os dados mostraram que faz-se necessário desmantelar muitos obstáculos, combater o preconceito e medidas excludentes que dificultam o acesso e a permanência dessas pessoas nessa modalidade de ensino, pois em sua individualidade, todos têm o direito de obter o conhecimento necessário para o seu desenvolvimento. Desta forma foi possível perceber que o professor se encontra como pilar fundamental nesse processo de inclusão, que necessita de preparação para exercer a docência com sensibilidade e excelência para identificar as necessidades de cada aluno e a melhor forma de proporcionar-lhes a desejada e igualitária educação.

PALAVRAS-CHAVE: Inclusão. Educação superior. Acessibilidade. Professor-aluno.

ABSTRACT: This research presents a study on the inclusion in higher education and pedagogical practices that can contribute to the achievement of that inclusion, by pointing out the historic debt that Brazil has based on exclusion and segregation of people with disabilities who are in constant struggle for their rights, that being gradually secured have a greater focus on basic education and currently aims to involve more effectively to higher education. The qualitative research has used as a methodological procedure a bibliographical survey on the subject, as well as the check of national legal documents, which explain the Brazilian political commitments on constant struggle for achievement of educational inclusion and also social inclusion. The data showed that it is necessary to dismantle many obstacles, to combat prejudice and excluding measures that hinder access and permanence of these people in this teaching mode, because in their individuality, everyone has the right to obtain the necessary knowledge for their development. Thus, it was possible to notice that the professor finds himself as a fundamental pillar in the process of inclusion that requires preparation for practice teaching with sensitivity and excellence to identify the needs of each student and the best way to provide them with the desired and equal education.

KEYWORDS: Inclusion. Higher education. Accessibility. Teacher-student. 


\section{Introdução}

O conceito de Educação Inclusiva é uma questão muito discutida no meio educacional em todos os níveis. O Decreto Lei 3298/99 em seu art. $2^{\circ}$ promulgou sobre a inclusão: "Cabe aos órgãos e às entidades do Poder Público assegurar à pessoa portadora de deficiência o pleno exercício de seus direitos básicos, inclusive dos direitos à educação". Após a publicação do Decreto supracitado, que regulamenta a Lei nº 7.853 de 1989, o Brasil se comprometeu a transformar o seu sistema educacional, tornando a Educação Inclusiva uma nova realidade, assegurando às pessoas com deficiências, transtornos globais do desenvolvimento e altas habilidades/superdotação, entre outros direitos básicos, o direito à educação.

Diante dessa realidade, o Ministério da Educação/Secretaria de Educação Especial apresentou a Política Nacional de Educação Especial na Perspectiva da Educação Inclusiva (2008), que trouxe novas concepções à atuação da Educação Especial no sistema de ensino, e a Inclusão Escolar passou a ser um desafio em todos os níveis educacionais, desde a Educação Básica até a Educação Superior. Neste nível acadêmico, a Educação Superior, a discussão desta temática ainda é escassa e com necessidade de reflexões mais sistemáticas, que considere as condições de acessibilidade e identificação do público dentro da universidade, para sistematizar as ações na perspectiva de identificar a demanda e prover os recursos necessários para possibilitar além do acesso a permanência e conclusão do curso.

Os desafios ainda são grandes, mas as alternativas que surgem possibilitam o acesso. A universidade é pensada como um espaço democrático, formadora de opiniões e produtora de conhecimento, que deve contribuir para eliminar as barreiras que impede a participação efetiva de estudantes público-alvo da Educação Especial, visto que esta população está chegando nessa modalidade de ensino e movimentando a prática acadêmica na universidade. Nessa perspectiva, a atual Lei de Diretrizes e Bases da Educação Nacional, Lei no 9.394/96, no artigo 59, propõe aos sistemas de ensino que estes devem assegurar aos alunos currículo, métodos, recursos e organização específicos para atender às suas necessidades.

Quanto ao papel do professor como mediador do processo ensino-aprendizagem desse público, a formação desse profissional se tornou um dos pontos cruciais na Educação Inclusiva. 
[...] a formação continuada representa um espaço-tempo de constituição e reflexão da ação educativa. É um espaço de potencialização das práticas pedagógicas. Uma oportunidade para (re)pensar as relações de poder existentes no currículo, os mecanismos utilizados para validar os conhecimentos e os pressupostos que fundamentam quem pode ou não aprender na escola. (MIRANDA, GALVÃO FILHO, 2012, p. 18)

Desse modo, os desafios encontrados pelo professor no dia a dia da educação se tornarão um espaço de desenvolvimento e expansão das práticas pedagógicas, objetivando a busca de informações, na qual dúvidas, necessidades e incertezas acontecerão no ambiente educacional, e o professor terá um importante papel no delineamento de caminhos para construção do aprendizado, visto que, apesar de documentos legais que apoiam e orientam as necessidades pedagógicas, tais situações ainda são recentes nesta modalidade de ensino, e como acontece com a formação humana, não existe uma fórmula determinada para adquirir o conhecimento.

Apesar da grande responsabilidade, o docente não é único neste desafio, citando a Educação Superior como foco da pesquisa, ele possui apoio pedagógico do núcleo de acessibilidade que surgiu inicialmente nas universidades federais por intermédio do programa lançado pelo Ministério da Educação e Cultura em 2005 - o Programa de Acessibilidade na Educação Superior - programa este intitulado INCLUIR, que visa o acesso, a permanência e conclusão do estudante nesta modalidade de ensino.

\section{Método}

Considerando os aspectos levantados acima, desenvolvemos uma pesquisa teórica de abordagem teórica qualitativo, por intermédio de pesquisa bibliográfica, baseando-se em estudos de diversos autores a respeito da inclusão e exclusão escolar; os desafios das universidades para cumprirem com as legislações que garantem acessibilidade à Educação Superior no Brasil; uma investigação e comparativo do número de inscrições na Educação Superior do Público-Alvo da Educação Especial, a capacitação dos profissionais que atuam nas salas de aulas com esses alunos e se há cooperação por parte de todos os envolvidos para o sucesso dessa educação, apresentando as diretrizes que trouxeram o programa INCLUIR para a Educação Superior e se houve contribuição para o processo de inclusão. Enfatizamos as pesquisas 
de (MAZZONI, 2003), (MARIANTE, 2008) e (SANTOS, 2013) que relatam a interação entre docente e discente.

\section{A inclusão e a educação superior}

Durante décadas a luta pela implementação da inclusão de pessoas Público-Alvo da Educação Especial (PAEE) - pessoas com deficiência, transtornos globais do desenvolvimento e altas habilidades/ superdotação, ocorreu inicialmente na Educação Básica, composta pela Educação Infantil, Ensino Fundamental e Ensino Médio;; mas a legislação garante a Educação Inclusiva em todos os níveis, oferecendo condições plenas de desenvolvimento, visando o acesso, a permanência e condições adequadas de aprendizagem. Para o acesso à Educação Superior desses alunos, segundo Pimentel, (2013) estão surgindo várias políticas afirmativas que são adotadas por instituições, como a disposição de atendimento apropriado aos estudantes que notificarem no ato da inscrição em processos seletivos a sua condição de aluno com necessidades específicas para acesso aos cursos de graduação.

Esse acesso e permanência na Educação Superior são reafirmados através da Política Nacional de Educação Especial na Perspectiva da Educação Inclusiva (BRASIL, 2008).

\footnotetext{
$\mathrm{Na}$ educação superior, a transversalidade da educação especial se efetiva por meio de ações que promovam o acesso, a permanência e a participação dos alunos. Estas ações envolvem o planejamento e a organização de recursos e serviços para a promoção da acessibilidade arquitetônica, nas comunicações, nos sistemas de informação, nos materiais didáticos e pedagógicos, que devem ser disponibilizados nos processos seletivos e no desenvolvimento de todas as atividades que envolvem o ensino, a pesquisa e a extensão. (BRASIL, 2008, p. 17)
}

É possível perceber uma valorização da sociedade inclusiva nos dias atuais. Os avanços sociais, pedagógicos e tecnológicos, com a criação de salas de recursos, métodos didáticos tecnológicos, metodologia diferenciada e atendimento especializado, afirmam essa realidade que ocorre também nas universidades.

Dados do Censo de 2013- MEC/INEP mostram o crescimento de matrículas conforme figura1, abaixo. 


\section{Figura 1}

\section{Evolução das matrículas de estudantes com deficiência na educação superior}

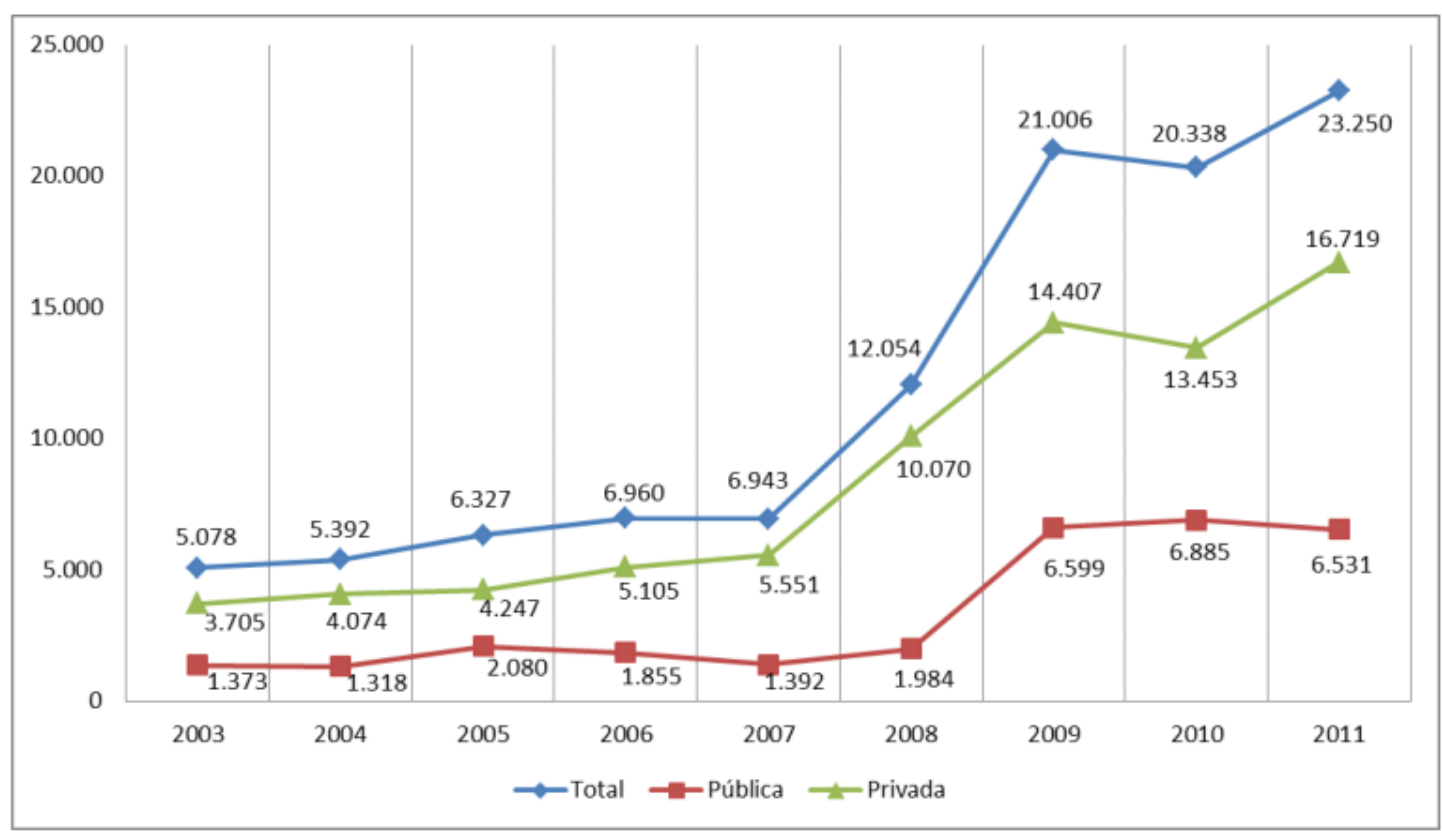

Fonte: http://portal.mec.gov.br/

"As matrículas de portadores de deficiência aumentaram quase 50\% nos últimos quatro anos, sendo a maioria em cursos de graduação presenciais. Em 2013 eram quase 30 mil alunos, enquanto em 2010 eram pouco mais de 19 mil" (BRASIL, 2014). Apesar do crescente número de matrículas realizadas ao longo dos anos, nem todos os candidatos à vaga conseguem ingressar em um curso superior, pois ainda existe desigualdade de oportunidades na oferta do processo seletivo, e instrumentos de avaliação utilizados pela instituição, em análise da inscrição e prova para ingresso.

[...] dados do Censo da Educação Superior do ano de 2011 demonstram que, em um universo de 6.739 .689 estudantes com matrícula, apenas 23.250 apresentam algum tipo de necessidade especial, sendo, o que equivale a um percentual de $0,35 \%$ das matrículas, assim distribuídos: 22160 com deficiência, 137 com Transtornos Globais do Desenvolvimento e 953 com Altas Habilidades/Superdotação. (BRASIL, 2013, p. 4)

Segundo (BRASIL, 2013, p. 4), "na educação superior o debate sobre a inclusão se inscreve na discussão mais ampla do direito de todos à educação e na igualdade de oportunidades de acesso e permanência, com sucesso, nessa etapa de ensino". Independente dos avanços já citados, a realidade ainda é lastimável, pouquíssimos 
alunos do ensino básico realizam a matrícula para ingressarem nessa etapa do ensino, e dos que ingressam, muitos acabam desistindo no decorrer do curso, pois este aluno da Educação Básica nem sempre foi preparado para almejar a universidade, a história da escolarização acentua a ideia da falta de capacidade por parte desses alunos, onde o acesso à Educação Superior só é possível após aprovação em árduo e longo processo seletivo, tornando esse o motivo de apenas cumprirem o proposto pela legislação, transmitindo conteúdo apresentado no ciclo de estudos, sem a idealização de adquirir habilidades e competências para novas etapas de ensino e possibilidades de inserção no mercado de trabalho.

Educar o aluno da Educação Básica na escola inclusiva visa reverter a exclusão e proporcionar a aceitação das diferenças, com o objetivo de impulsionar o sujeito para o futuro, possibilitando a conclusão da Educação Básica como sendo apenas o encerramento de um ciclo e o início de uma nova etapa de conquista.

\section{A profissionalização do corpo docente}

O docente é o elemento crucial no processo ensino-aprendizagem, portanto “Assegurar que os professores recentemente qualificados tenham uma compreensão básica do ensino inclusivo e de escolas inclusivas é o melhor investimento que pode ser feito a longo prazo" (MITTLER, 2003, p.189), o que propõe uma ressignificação na forma de trabalho pela experiência docente, reestruturação e mobilização das práticas pedagógicas.

Proporcionar ao aluno PAEE aprendizagem em meio à situação de equidade aos demais alunos da sala de aula também é papel do professor, e requer deste profissional preparação, capacitação e orientação, oferecendo assim, confiança no atendimento ao aluno, sem causar resistência na comunicação e prejuízos na vida acadêmica. Nesse contexto, (MIRANDA, GALVÃO FILHO, 2012, p.12) argumentam que "o educador terá a tarefa de prever e preparar recursos capazes de ativar a elaboração e a circulação de informações entre sujeitos, de modo que se reconheçam e se auto organizem". Assim, podemos afirmar que a relação educativa se constitui, como tal, na medida em que, se o aluno não tem apoio necessário, passa para a posição de observador, o que acaba contribuindo para sua exclusão. 
Segundo Stainback (1999, p. 25) "o que está em questão no ensino inclusivo é ser oferecido aos alunos os serviços de que necessitam, mas em ambientes integrados, e em proporcionar aos professores atualização de suas atividades". Os futuros profissionais da educação cursam licenciatura e ao término do curso não estão preparados para tal realidade, enquanto estudantes realizam os estágios, porém não adquirem experiências que lhe capacitarão para atuarem no ensino de crianças com necessidades especiais;; nessa reflexão, a Lei de Diretrizes e Bases da Educação Brasileira (LDB 9394/96), aprovada em 20 de dezembro de 1996 em seu art.59 inciso III determina que os professores deverão ter especialização adequada para atuarem na Educação Especial tanto no ensino médio quanto no superior, porém o que ocorre são professores atuando em salas com alunos público-alvo da educação especial sem preparação específica.

O professor pode ser considerado um elemento fundamental na organização de espaços educacionais mais apropriados, porém ele não é o único responsável por essa mudança e reorganização do ensino, é de extrema importância que haja uma participação em equipe, sociedade, coordenadoria da instituição educacional e corpo docente, para que bons resultados sejam obtidos. Assim, Santos (2013) evidencia a

[...] responsabilidade do processo de inclusão educacional do coletivo para o individual, na medida em que coloca no professor e na escola/universidade o ônus pela tarefa de se garantir as condições de acessibilidade pedagógica e física de todo processo educacional para todas as pessoas. (SANTOS, 2013, p. 81).

Além da participação nas atividades acadêmicas, para que se consiga conquistar uma educação inclusiva bem-sucedida, se faz necessário seguir um conjunto de leis, mudanças, comportamentos e princípios, não basta mudar a estrutura da escola se os profissionais da educação não conseguem mudar ou diversificar o seu método de ministrar aulas, não basta ter leis, se essas não forem seguidas pelos cidadãos ou fiscalizadas pelo governo.

Mesmo após o Decreto que regulamentou e instituiu educação para todos, os professores se deparam com a falha do sistema na educação por não terem a oportunidade de se exporem durante sua formação à práticas e ao ensino nas escolas para alunos com necessidades educacionais especiais.

Para que o aluno PAEE consiga boa adaptação na universidade é preciso que encontre em sala de aula meios de acessibilidade física e curricular em condições de 
promover a aprendizagem sem transtornos. $\mathrm{O}$ acesso físico, aqui relatado, não se refere apenas à sala de aula, mas todos os ambientes da instituição, como bibliotecas, laboratórios, restaurantes, etc. A instituição precisa fornecer ao professor ambiente adequado de trabalho e este precisa adquirir conhecimentos específicos para trabalhar.

Ações de inclusão na Educação Superior envolvem o planejamento e a organização de recursos e serviços para a promoção da acessibilidade arquitetônica, nas comunicações, nos sistemas de informação, nos materiais didáticos e pedagógicos, que devem ser disponibilizados desde os processos seletivos ao desenvolvimento de todas as atividades que envolvem o ensino, a pesquisa e a extensão.

Nos diversos desafios encontrados pelo docente, este pode recorrer ao núcleo de acessibilidade sempre que necessário, para orientações, pois as ações do núcleo estão atreladas com o apoio pedagógico dos docentes, a fim de efetivar os direitos legais dos alunos. Sem esse apoio, as ações voltadas para o sucesso da inclusão na Educação Superior tornam-se cada vez mais diminutas. No entanto, o núcleo de acessibilidade não é uma realidade em todas as universidades brasileiras, o que dificulta o trabalho do professor e a participação do aluno.

\section{Acessibilidade na educação superior}

Em 2005 o MEC lançou o Programa de Acessibilidade na Educação Superior INCLUIR, por meio de editais, cujo objetivo era promover a inclusão de estudantes com deficiência na Educação Superior, possibilitando a acessibilidade nas universidades federais, fornecendo recursos financeiros.

O referido Programa prioriza as estratégias de acessibilidade, mas não legisla especificamente entre elas. Seu norteamento se limita à abertura de Editais e à seleção de projetos das universidades concorrentes, culminando no patrocínio financeiro dos projetos selecionados. (FERREIRA, 2012, p. 95)

Fica sob a responsabilidade das instituições federais desenvolverem seus projetos e idealizarem suas políticas inclusivas, e após a seleção do projeto recebem recursos financeiros para promover a ação. Tal programa visa a qualidade da aprendizagem de alunos com necessidades educacionais especiais, garantindo a igualdade de oportunidades e pleno acesso à educação formal seguindo os quatro eixos: 
Infraestrutura - Adequação arquitetônica nas edificações através de rampas, piso tátil, corrimão e barra de apoio, elevadores e outras adequações que permitam o acesso em todos os ambientes e garanta o direito de ir e vir com segurança.

Currículo, comunicação e informação - Garantir a acessibilidade pedagógica com aquisição de recursos didáticos e mobiliário acessível que promova a comunicação e informação, disponibilizando materiais pedagógicos como: máquinas em Braille, computadores com interface de acessibilidade e outros.

Programas de extensão - Disseminar a acessibilidade por ações de extensão, com a participação da comunidade visando construir uma sociedade inclusiva.

Programas de pesquisa - Abranger as inúmeras áreas do conhecimento fundamentadas no princípio da transversalidade para o progresso da inclusão social.

No edital de 2009 acontece à alteração da nomenclatura IFES (Instituições Federais de Ensino Superior) para Instituições Públicas de Educação Superior, o que permite a concorrência das Instituições Estaduais (SOUZA, 2010, p.67). As publicações dos editais do programa visam implantar ações para que os estudantes público-alvo da educação especial tenham acesso à educação formal comtemplando ações de acessibilidade, como adequação arquitetônica, incluindo adaptação em sanitários, alargamento nas portas, piso tátil, construção de rampas, aquisição de mobiliário acessível e formação do profissional para atuar em práticas educativas através de cursos preparatórios.

Até 2011, a participação no programa se dava por editais e, em 2012, a ação foi universalizada, atendendo a todas as Instituições de Educação Superior;; conforme os Referenciais de Acessibilidade na Educação Superior e a Avaliação in loco do Sistema Nacional de Avaliação da Educação Superior - SINAES (BRASIL, 2013) cabe às instituições de Educação Superior, tanto públicas quanto privadas, a organização dos Planos de Desenvolvimento Institucional e Projetos Pedagógicos de Curso com a inserção da Educação Inclusiva, bem como a implementação de Núcleos de Acessibilidade para estudantes Público-alvo da Educação Especial.

[...] compreende-se por Núcleos de Acessibilidade, a constituição de espaço físico, com profissional responsável pela organização das ações, articulação entre os diferentes órgãos e departamentos da universidade para a implementação da política de acessibilidade e efetivação das relações de ensino, pesquisa e extensão na área. Os Núcleos deverão atuar na implementação da acessibilidade às pessoas com deficiência em todos os espaços, ambientes, materiais, ações e 
processos desenvolvidos na instituição. As ações desenvolvidas pelo Núcleo deverão integrar e articular as demais atividades da instituição, como os projetos de pesquisa, estudo, intercâmbio, cooperação técnico-científica e extensão e ensino para a inclusão educacional e social das pessoas com deficiência. (BRASIL, 2007, p. 4)

O programa INCLUIR, além de possibilitar aos estudantes deficientes o acesso à Educação Superior, se revela como uma iniciativa governamental para este público. O programa repassa às instituições superiores a responsabilidade de criação e estruturação de núcleos de acessibilidade com o papel de articular políticas inclusivas, disponibilizar apoio e orientação às coordenações de cursos, oferecer apoio didático não somente ao aluno, mas principalmente aos professores. É possível perceber sua extrema valia para que a inclusão realmente aconteça nas instituições.

Tais requisitos devem ser implantados, mas em nenhuma hipótese poderá ser cobrada taxas para os alunos ou familiares pelos serviços prestados e materiais adquiridos.

[...] nos anos mais recentes constatamos que foram propostos $\mathrm{o}$ PROUNI e o INCLUIR, que de certa forma contribuem para a ampliação do acesso dos brasileiros historicamente excluídos das instituições de ensino superior brasileiras. No entanto, estas ações ainda são insuficientes para reverter o quadro de exclusão na educação superior da pessoa com deficiência, sendo necessárias outras ações, para que mais pessoas com deficiências possam adentrar nos espaços acadêmicos, com possibilidade de aprendizagem e conclusão de curso. (CALHEIROS, FUMES, 2011, p. 71)

É possível perceber que o modelo de Educação Inclusiva é referendado por políticas públicas, que visa o acesso pleno do educando, mas a inclusão exige além de documentos como direcionamento, exige análise diária em ambiente escolar, para que as especificidades do público-alvo da Educação Especial sejam contempladas em espaços heterogêneos, proporcionando condições para a construção do conhecimento.

\section{Interação professor - aluno}

A sala de aula é um ambiente onde deve ocorrer interações entre professores e alunos. Um bom relacionamento entre docente e discente resultará na certeza de que o mesmo pode procurar seu professor como alguém disposto a lhe auxiliar em todas as 
objeções. "Uma conversa sensível e aberta permitirá ao professor compreender quais são as estratégias já desenvolvidas pelo aluno para minimizar suas dificuldades e valorizar seu potencial. O próprio aluno terá sugestões valiosas a dar" (VALENTINI, 2012. p. 36). Através do diálogo e observação é possível conhecer o alunado e suas necessidades de aprendizagem, com o objetivo de desenvolvê-los plenamente conforme as propostas educacionais.

Mazzoni (2003) em sua tese, "Deficiência X Participação: Um desafio para as Universidades" entrevistou alunos da Educação Superior com necessidades educacionais especiais e apresentou dados da relação professor-aluno.

A relação entre os alunos sujeitos da pesquisa e seus professores assume diferentes matizes que envolvem sentimentos de pena, respeito, admiração e atitudes como superproteção, indiferença e rejeição. Um dos entrevistados relatou que inclusive alguns professores o ajudaram a compreender-se melhor como pessoa: "Alguns me fizeram falar do problema que eu tinha para toda a turma". (MAZZONI, 2003, p.135)

Conforme a pesquisa citada, os alunos relataram conflitos com seus professores e afirmam o despreparo dos mesmos, mencionado no "depoimento de uma pessoa surda profunda que percebia que o professor aumentava o tom da voz quando falava com ela" (MAZZONI, 2003, p.137). O desinteresse também é elencado: “Um aluno surdo oralizado relatou que apenas um dos seus professores procurou saber como poderia ajudá-lo em sala de aula" (MAZZONI, 2003, p.138). Os alunos apresentaram falhas nas práticas pedagógicas de professores despreparados para atendê-los, que não buscaram materiais diferenciados e julgaram não ser de sua responsabilidade tal atitude. Docentes agem de maneira natural como se estes alunos não estivessem na sala, movimentam-se, gesticulam e não informam verbalmente os fatos acontecidos, dentre outras posturas.

Com a mesma linha de pesquisa Mariante (2008) apresenta em sua dissertação entrevista com docentes e discentes para análise do processo pedagógico e afirma que "diante do desafio de falar sobre a avaliação praticada, que os entrevistados docentes e discentes são unânimes em dizer que não há uma proposta diferente para alunos com NEEs, sendo, portanto, igual para todos" (MARIANTE, 2008, p.85).

Ainda citando a avaliação, elaborada pelos professores, os alunos relatam que 
aluno" (Discente E4). Mesmo com essa constatação, alguns apontam para atitudes diferenciadas de apoio, quando dizem: "sempre dão alguém "prá" te ajudar" (Discente E2), "eles "tão" sempre abertos "prá" ouvir alguma reclamação ou tipo de exigência" (Discente E2), "fica claro o interesse deles na minha aprendizagem" (Discente E4). Também é evidenciada uma crítica quanto à metodologia utilizada não só em momentos avaliativos, quando o Discente E1 diz "mania de fazer roda e aí eu não enxergava a boca dos colegas". (MARIANTE, 2008, p. 81)

Para ocorrer a inclusão na Educação Superior, é necessário que os docentes reconheçam que os alunos não são todos iguais, a diversidade está presente também em sala de aula. Alguns apresentam mais dificuldade de entendimento em disciplinas práticas, outros em disciplinas teóricas, independente das necessidades especiais que é o foco desta pesquisa, cada aluno é único e possui suas preferências, facilidades e dificuldades. Cabe aos docentes admitirem a existência da diversidade nas salas de aulas e recriarem suas didáticas de ensino, adotando uma postura renovadora que trará impactos práticos na vida de todos os alunos, pois diante de alunos diferentes não é possível utilizar modelos de ensino iguais.

Santos (2013) evidencia que apesar de novas conquistas quanto á prática pedagógica de professores, nem todos reconhecem essa realidade.

[...] constatamos nas falas dos alunos que elas são variadas. Existem tantos professores que planejam as suas aulas sem considerar o aluno com deficiência (ao apresentar filmes sem legendas, PowerPoint, gráficos sem adequações, etc.), os inflexíveis no momento da avaliação quanto os que se preocupam em organizar sua prática pedagógica (aspectos didáticos, conteúdo, avaliação, materiais, etc.) adequada às condições de acesso e ensino aprendizagem dos alunos em sala de aula. (SANTOS, 2013, p. 247)

Em todos os níveis de ensino a metodologia utilizada em sala de aula envolve os alunos ditos normais, mas esta padronização está longe de ser o modelo ideal, se uma pergunta for proposta para determinado número de alunos em sala de aula, a resposta não será a mesma, portanto é preciso considerar as diferentes formas de aprender desses alunos, ter um olhar natural diante das diversidades e aceitação das diferenças, com metodologia que unifique a teoria e prática e promova a interação. Também é importante ressaltar que "a falta de acessibilidade na sala de aula prejudica o desenvolvimento das atividades acadêmicas do aluno com deficiência e, muitas vezes, tem como consequência a evasão dele da universidade" (SANTOS, 2013, p.249). 
As citações de Mazzoni (2003) evidenciam que durante este período o professor despreparado apenas expunha o aluno perante a sala de aula ao fazê-lo contar sobre suas necessidades. O fato de reconhecê-lo como aluno com necessidades especiais era suficiente para este se sentir incluído. Na citação apresentada, é possível perceber a falta de preocupação em relação aos materiais necessários para a aula ou sobre o método de ensino, demonstrando que tal estudante estava inserido, mas sem preparo e condições para oferecer-lhe um ambiente adequado de estudos, apenas sendo cumprido o determinado por lei.

A pesquisa de Mariante (2008) não revela muitas alterações, a metodologia de ensino ainda continua sendo a mesma para todos os alunos, apenas enfrentam a situação como uma realidade, aceitam reclamações e buscam mecanismos de aprendizagem pelos próprios alunos, solicitando que colegas os ajudem quando necessário. O processo educativo começa a ser fator de análise, mas sem muitas condições e informações por parte dos docentes.

Podemos dizer que atualmente, considerando as entrevistas citadas por Santos (2013) e visando o longo período de busca por acessibilidade, a pesquisa mencionada pode ser considerada recente, e lamentavelmente ela não apresenta resultados satisfatórios quanto à inclusão, pois apesar do avanço em políticas públicas e conscientização da população, a realidade enfrentada em sala de aula não garante total acesso, tendo ainda alguns percalços, como o citado pela autora "de mudar a prática pedagógica, ou seja, àquilo que já virou hábito, rotina[...] (SANTOS, 2013, p. 297) .

Portanto, esse caminho ainda está longe de um final satisfatório: trilha seus passos não para o sucesso, mas para a acessibilidade necessária.

\section{Conclusões}

A diversidade marca presença também na Educação Superior, na sala de aula como espaço heterogêneo, embasado na legislação que garante o acesso desses alunos da Educação Básica a Superior, mas inclusão é muito mais que disponibilizar rampas e banheiros adaptados, é reconhecer e respeitar as diferenças, é desenvolver projeto pedagógico coerente com as necessidades educacionais, compromisso ético, tendo em vista o acesso ao conhecimento. 
Diante deste cenário, é evidente a importância do professor como mediador de aprendizagem, que além de proporcionar meios para interação, possibilitando a busca e construção da aprendizagem, tem como responsabilidade verificar melhores condições de acesso, pois é dentro da sala de aula que as diferentes necessidades aparecem. Assim, o diálogo com os demais docentes, a coordenação escolar, grupo pedagógico, direção, faz-se necessário para a troca de experiências e sugestões, visto que são muitos os obstáculos a serem superados.

É preciso, entre outras práticas, compromisso ético por parte desses profissionais da educação em todas as etapas do ensino, para que os alunos público-alvo da educação especial tenham acesso ao conhecimento e ao ingressarem na Educação Superior consigam alcançar sua formação, tornando realidade o que a legislação promulgou quanto á educação para todos.

Os riscos consequentes das mudanças e da prática no dia a dia da instituição não podem paralisar ou provocar desânimo nesse profissional, a tal ponto que não visualize os pontos positivos do seu intenso empenho. Portanto, a Educação Inclusiva no Brasil é um processo em construção, que luta por uma sociedade mais justa e humanitária, onde o professor é a 'peça' fundamental do projeto de reconstrução social, mesmo que de maneira incipiente através da educação.

\section{Referências}

BRASIL. Decreto n. 3.298 de 20 de dezembro de 1999. Regulamenta a Lei no 7.853 , de 24 de outubro de 1989, dispõe sobre a Política Nacional para a Integração da Pessoa Portadora de Deficiência, consolida as normas de proteção, e dá outras providências. Brasília. Disponível em: < http://www.planalto.gov.br/ccivil_03/decreto/d3298.htm>. Acesso em: 07 set. 2015.

Decreto $n^{0}$ 5.626 de 22 de dezembro de 2005. Regulamenta a Lei $n^{0} 10.436$, de 24 de abril de 2002, que dispõe sobre a Língua Brasileira de Sinais - Libras, e o art. 18 da Lei $\mathrm{n}^{\mathrm{o}}$ 10.098, de 19 de dezembro de 2000. Disponível em <http://www.planalto.gov.br/ccivil_03/_ato2004-2006/2005/decreto/d5626.htm>.

Acesso em: 12 out. 2015.

Lei 9394/96. Lei de Diretrizes e Bases da Educação Nacional. Disponível em <//http://portal.mec.gov.br/arquivos/pdf/ldb.pdf>. Acesso em: 04 out. 2015.

Censo da Educação Superior Brasileira: Matrículas no Ensino Superior crescem 3,8\%. 2014. Disponível em: <http://portal.inep.gov.br/visualizar/- 
/asset_publisher/6AhJ/content/matriculas-no-ensino-superior-crescem-3-8>. Acesso em: 23 set. 2015.

Ministério da Educação. Secretaria da Educação Especial. Política Nacional de Educação Especial na Perspectiva da Educação Inclusiva. Brasília: MEC/SEESP, 2008. Disponível em:< http://portal.mec.gov.br/arquivos/pdf/politicaeducespecial.pdf $>$. Acesso em: 23 set. 2015.

Ministério da Educação. Secretaria de Educação Superior, Secretaria De Educação Especial. Edital $n^{\circ} 3$. Programa Incluir: acessibilidade na educação superior. 26 de abril de 2007. Disponível em: < http://portal.mec.gov.br/index.php?option=com_docman\&view=download\&alias=813editalincluir-integra-2007-pdf\&category_slug=documentos-pdf\&Itemid=30192>. Acesso: em 31 set. 2015.

Referenciais de Acessibilidade na Educação Superior e a Avaliação in loco do Sistema Nacional de Avaliação da Educação Superior (SINAES), Parte I Avaliação de cursos de graduação. Brasília: MEC/INEP/DAES, 2013. Disponível em:〈http://www.ampesc.org.br/_arquivos/download/1382550379.pdf >. Acesso em: 22 set. 2015.

Brasil, Portaria Normativa $\mathbf{N}^{\mathbf{1}}$ 14, DE 24 DE ABRIL DE 2007, FERNANDO HADDAD. Disponível em: <http://portal.mec.gov.br/arquivos/pdf/ programa_incluir.pdf $>$. Acesso em 17 set. 2015.

Portaria $\mathbf{n}^{\mathbf{0}} \mathbf{3 . 2 8 4}$ de 07 de novembro de 2003. Dispõe sobre requisitos de acessibilidade de pessoas portadoras de deficiências, para instruir os processos de autorização e de reconhecimento de cursos, e de credenciamento de instituições. Disponível em: <http://portal.mec.gov.br/seesp/arquivos/pdf/port3284.pdf〉. Acesso em 12 out, 2015.

\section{Programa Incluir. Documento Orientador Programa Incluir} Acessibilidade na Educação Superior SECADI/SESu-2013. Disponível em: < http://portal.mec.gov.br/index.php?option=com_docman\&view=download\&alias $=1329$ 2-doc-ori-progincl\&category_slug=junho-2013-pdf\&Itemid=30192>. Acesso em: 18 set. 2015

CALHEIROS, D. S.; FUMES, N. L. F. O (a) aluno (a) com deficiência nas instituições de ensino superior da cidade de Maceió/AL. Debates em Educação, Maceió, Vol. 3, no 5, p.01-19, jan./jun. 2011.

FERREIRA, N. M. C. Educação inclusiva no ensino superior: análise de políticas educacionais para a pessoa com deficiência na Universidade Federal do Maranhão. 2012. 125 f. Dissertação (Mestrado em Educação) - Programa de Pós-Graduação em Educação, Universidade Federal do Maranhão, Maranhão, 2012.

MARIANTE, A. B. A avaliação da aprendizagem de estudantes do ensino superior com necessidades educativas especiais: entre a teoria e a prática docente. $2008.120 \mathrm{f}$. Dissertação (Mestrado em Educação) - Programa de Pós-Graduação em Educação, Pontifícia Universidade Católica do Rio Grande do Sul, Porto Alegre, 2008. 
MAZZONI, A. A. Deficiência x Participação: Um desafio para as Universidades. 2003. 245 f. Tese (Doutorado em Engenharia de Produção). Centro TecnológicoPrograma de Pós-Graduação em Engenharia de Produção, Universidade Federal de Santa Catarina, Florianópolis, 2003.

MIRANDA, T.G.; GALVÃO FILHO, T.A. (Orgs). O professor e a educação inclusiva: formação, práticas e lugares. Salvador: EDUFBA, 2012.

MITTLER, P. Educação inclusiva: contextos sociais. Porto Alegre: Artmed, 2003.

PIMENTEL, S.C. (Orgs) Estudantes com deficiência no Ensino Superior: construindo caminhos para desconstrução de barreiras na UFRB. Cruz das Almas/BA: NUPI, PROGRAD, UFRB, 2013. 24p. Disponível em: < http://www1.ufrb.edu.br/nupi/images/documentos/Estudantes\%20com\%20deficincia\%2 0no\%20Ensino\%20Superior\%20construindo\%20caminhos\%20para\%20in.pdf $>$. Acesso em: 18 set. 2015 .

SANTOS. C. S. Políticas de acesso e permanência de alunos com deficiência em universidades brasileiras e portuguesas. 2013. 389 f. Tese (Doutorado em Educação), Universidade Federal de Uberlândia. Uberlândia, 2013.

STAINBACK, S.; STAINBACK, W. Inclusão: um guia para educadores. Porto Alegre: Artmed, 1999.

SOUZA, B. C. S. Programa INCLUIR (2005 -2009): uma iniciativa governamental de educação especial para a educação superior no Brasil. 2010. 179f. Dissertação (Mestrado em Educação) - Centro de Ciências da Educação, Universidade Federal de Santa Catarina, Florianópolis, 2010.

VALENTINI, C. B. Inclusão no Ensino Superior: especificidades da prática docente com estudantes surdos. Caxias do Sul, RS: Educs, 2012.

\section{Como referenciar este artigo}

CANDIDO, Eliane Aparecida Piza.; NASCIMENTO, Claudia Regina Siena do NASCIMENTO.; MARTINS, Morgana de Fátima Agostini. Acessibilidade na educação superior também envolve o trabalho pedagógico. Revista Ibero-Americana de Estudos em Educação, v. 11, n. esp. 2, p.1017-1033, 2016. Disponível em: <https://dx.doi.org/10.21723/riaee.v11.esp2.p1017-1033>. E-ISSN: 1982-5587.

\section{Sobre os autores}

i Aluna Especial. UNESP - Universidade Estadual Paulista. Faculdade de Ciências e Letras - Pósgraduação em Educação Escolar. Araraquara - SP - Brasil. 14800-901 - pizaeliane@ hotmail.com 
ii Aluna Especial. UNESP - Universidade Estadual Paulista. Faculdade de Ciências e Letras - Pósgraduação em Educação Escolar. Araraquara - SP - Brasil. 14800-901 claudiasienanascimento@bol.com.br

iii UFGD - Universidade Federal da Grande Dourados. Faculdade de Educação - Pós-graduação em Educação. Dourados - MS - Brasil. 7984-970 - morganamartins@ ufgd.edu.br 